\title{
Diagnosis of occult fractures of the ischiopubic rami
}

\author{
Koji Suzuki \\ JA Toride Medical Center, Department of Orthopaedic Surgery, Toride, Japan \\ Email: kojisuzuki325282@,aol.com
}

Received 14 January 2013; revised 22 February 2013; accepted 28 February 2013

\begin{abstract}
Introduction: Recently, the diagnosis of occult fractures has been facilitated due to increased availability and utilization of MRI. Diagnosing a fracture of the ischiopubic rami from a proximal femoral fracture, in particular, is difficult using physical exam alone and can be facilitated by having access to an MRI. Here we report both physical exam findings and MRI findings that help in differentiating occult fractures of the iliopubic rami. Materials and Methods: From April 2010 to December 2012, we identified 30 patients (5 male and 25 female; aged 43 - 93 years old). We recorded if a traumatic episode occurred, ambulatory status at the initial visit (bed ridden, standing up with an aid, walking with an aid). We also recorded if imaging was used in determining the final diagnosis (radiographs, MRI or CT). Results: Twentyone patients had a fracture as a result of a traumatic episode. In the remaining 9 cases, no trauma occurred and therefore the fractures were insufficiency fractures. Ten patients were bed ridden at the initial visit, eight patients were able to stand only with a walking aid, and the remaining twelve patients were able to walk with an aid. Occasional radiographs were used to confirm the presence of a fracture in $\mathbf{4}$ cases, MRI in 11 cases, and CT scan in 15 cases. Discussion and Conclusions: Occult fractures of the ischiopubic rami can occur without trauma and it can be difficult to differentiate these fractures from occult proximal femoral fractures. In these cases, MRI is useful to definitively obtain a diagnosis. In cases of pacemaker, bullet implantation or artificial hip joints, CT or occasional radiographs are also useful to diagnose occult fractures of the ischiopubic rami.
\end{abstract}

Keywords: Occult; Diagnosis; Pelvis

\section{INTRODUCTION}

Increased availability of Magnetic Resonance Imaging (MRI) and Computed Tomography (CT) scanning in recent years has facilitated the diagnosis of occult frac- tures. Because the ischiopubic rami located near the proximal femur, differentiating the fracture of the ischiopubic rami from a proximal femoral fracture is difficult. Especially in occult fractures, we could not detect shortening of leg length and bony deformity. To detect an occult fracture, nuclear medicine techniques were previously used [1-6]. However, differentiating a fracture of the ischiopubic rami from a proximal femur fracture can still be difficult. Distinguishing a fracture of the ischiopubic rami from a proximal femur fracture is important in determining conservative versus surgical treatment. We report both physical exam findings and MRI findings that help in differentiating occult fractures of the iliopubic rami.

\section{PATIENTS AND METHODS}

We identified 30 patients with occult fractures of the ischiopubic rami from April 2010 to December 2012. At the initial visit we suspected a fracture around the hip; however, a fracture line was not detectable on a plain radiograph. We investigated the incidence of trauma and the ambulatory status at the initial visit (bed ridden, standing up with an aid, and walking with an aid) and then analyzed images to determine the final diagnosis (repeated radiograph, MRI, CT).

An MRI was performed within 7 days from the time of clinical presentation. Axial T1- and T2-weighted spin echo images were obtained using a Siemens $1.5 \mathrm{~T}$ system (Synphony, Siemens AG, Erlangen, Germany). We defined low intensity areas within bone marrow in $\mathrm{T} 1 \mathrm{im}$ ages as fractures [1]. CT studies were performed within 7 days from the time of clinical presentation. Axial images were performed using a GE HiLight Scanner (GE Medical Systems, Milwaukee, WI, USA). The slice thickness ranged from 2 to $3 \mathrm{~mm}$. All studies were performed with $120 \mathrm{kVp}$ and milliampere values ranging from 150 to $300 \mathrm{~mA}$. We defined a low intensity line within bone marrow or a cortical discrepancy as a fracture.

Conservative management was applied in all cases. We did not restrict activities of daily living and permitted weight bearing as tolerated. We prescribed analgesics occasionally. We identified fracture healing within 2 
months.

\section{RESULTS}

Fall accidents occurred in 21 cases. We could not detect a traumatic episode in 9 cases with diagnoses of insufficiency fractures of superior pubic rami. At the initial visit, 10 patients were bed ridden, 8 patients were able to stand with an aid, and 12 patients were able to ambulate with an aid. MRI was utilized to determine the final diagnosis in 11 cases, CT in 15 cases, and repeated radiographs in 4 cases. A fracture site located near a hip implant was detected by repeated radiographs in 1 case. In 2 cases, we could not utilize MRI because of bullet implantation or existence of a pacemaker (Table 1).

\subsection{Cases}

\subsubsection{Case 1}

An 85-year-old female with chronic renal failure had a ground level fall and resultant left groin pain. At the initial visit, she could raise her leg in the supine position and walk with a push up walker. We did not detect a fracture line in this radiograph (Figures 1(a) and (b)). MRI indicated a diffuse low intensity area at the superior pubic ramus. One month later she could walk without assistive devices after a period of conservative treatment (Figures 2(a) and (b)).

\subsubsection{Case 2}

A 72-year-old female with lumbar degenerative kyphosis fell down and complained of left groin pain. We did not detect a fracture line in this radiograph. At the initial visit we suspected a proximal femoral fracture (Figures 3(a) and (b)). MRI indicates a diffuse low intensity area at the superior pubic ramus. MRI indicates a diffuse low intensity area at the superior pubic ramus (Figures 4(a) and (b)). One month later she could walk after a period of conservative treatment.

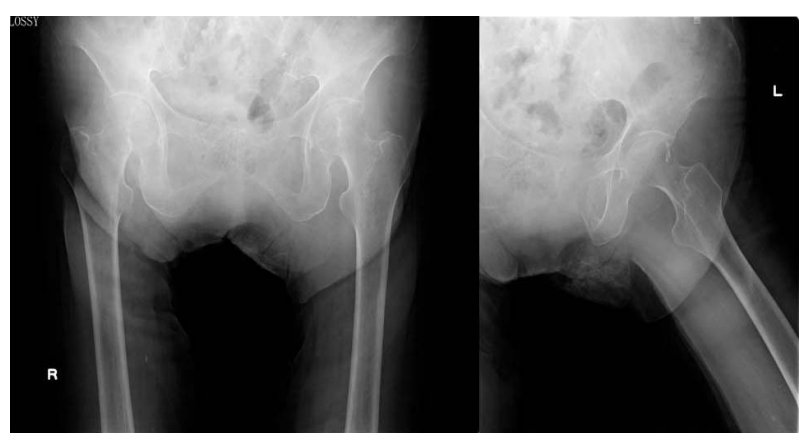

(a)

(b)

Figure 1. (a) Standard radiographs of an occult fracture at left superior pubic ramus in case 1; (b) Lateral view. We could not detect a fracture line in both the antero-posterior and lateral views.
Table 1. Details of study patients with occult fractures of the ischiopubic rami.

\begin{tabular}{|c|c|c|c|c|c|}
\hline & AGE & SEX & $\begin{array}{c}\text { Traumatic } \\
\text { episode }+/-\end{array}$ & $\begin{array}{c}\text { Ambulatiry status at } \\
\text { initial visit }\end{array}$ & Image \\
\hline 1 & 80 & $\mathrm{~F}$ & - & Walk with an aid & MRI \\
\hline 2 & 72 & $\mathrm{~F}$ & + & Walk with an aid & MRI \\
\hline 3 & 93 & $\mathrm{~F}$ & + & Bed ridden & $\mathrm{CT}$ \\
\hline 4 & 87 & M & + & Bed ridden & $\mathrm{CT}$ \\
\hline 5 & 88 & $\mathrm{~F}$ & + & Standing up with an aid & MRI \\
\hline 6 & 85 & $\mathrm{~F}$ & + & Standing up with an aid & MRI \\
\hline 7 & 43 & $\mathrm{~F}$ & - & Walk with an aid & $\mathrm{Xp}$ \\
\hline 8 & 80 & $\mathrm{~F}$ & - & Walk with an aid & $\mathrm{Xp}$ \\
\hline 9 & 80 & $\mathrm{~F}$ & + & Standing up with an aid & $\mathrm{Xp}$ \\
\hline 10 & 83 & $\mathrm{~F}$ & + & Walk with an aid & $\mathrm{CT}$ \\
\hline 11 & 86 & $\mathrm{~F}$ & + & Bed ridden & $\mathrm{CT}$ \\
\hline 12 & 61 & $\mathrm{~F}$ & + & Bed ridden & $\mathrm{CT}$ \\
\hline 13 & 91 & $\mathrm{~F}$ & + & Bed ridden & $\mathrm{CT}$ \\
\hline 14 & 80 & $\mathrm{~F}$ & - & Walk with an aid & MRI \\
\hline 15 & 75 & $\mathrm{~F}$ & + & Bed ridden & MRI \\
\hline 16 & 80 & $\mathrm{~F}$ & + & Standing up with an aid & $\mathrm{CT}$ \\
\hline 17 & 80 & M & + & Standing up with an aid & MRI \\
\hline 18 & 61 & M & + & Bed ridden & $\mathrm{CT}$ \\
\hline 19 & 63 & $\mathrm{~F}$ & - & Walk with an aid & $\mathrm{Xp}$ \\
\hline 20 & 72 & $\mathrm{~F}$ & + & Bed ridden & $\mathrm{CT}$ \\
\hline 21 & 83 & $\mathrm{~F}$ & + & Walk with an aid & MRI \\
\hline 22 & 84 & $\mathrm{~F}$ & - & Walk with an aid & MRI \\
\hline 23 & 65 & $\mathrm{~F}$ & - & Walk with an aid & $\mathrm{CT}$ \\
\hline 24 & 58 & $\mathrm{~F}$ & + & Walk with an aid & MRI \\
\hline 25 & 93 & $\mathrm{~F}$ & - & Standing up with an aid & $\mathrm{CT}$ \\
\hline 26 & 85 & M & + & Bed ridden & $\mathrm{CT}$ \\
\hline 27 & 89 & $\mathrm{~F}$ & - & Bed ridden & $\mathrm{CT}$ \\
\hline 28 & 57 & M & + & Standing up with an aid & $\mathrm{CT}$ \\
\hline 29 & 75 & $\mathrm{~F}$ & + & Walk with an aid & MRI \\
\hline 30 & 67 & $\mathrm{~F}$ & + & Standing up with an aid & $\mathrm{CT}$ \\
\hline
\end{tabular}

\subsubsection{Case 3}

An 87-year-old male with bullet implantation that occurred during World War 2 had a ground level fall followed by right groin pain. At the initial visit he could not walk without assistance. We did not detect a fracture line in a radiograph (Figures 5(a) and (b)). Due to bullet implantation, MRI was not recommended. Therefore, CT was 


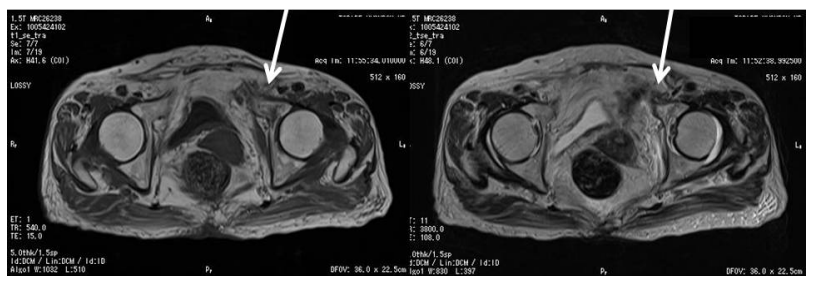

(a)

(b)

Figure 2. (a) On axial T1-weighted images, a fracture line extends leading towards the superior pubic ramus (white arrow); (b) On axial T2-weighted images, diffuse high intensity areas exist in the external obturator muscle (white arrow).

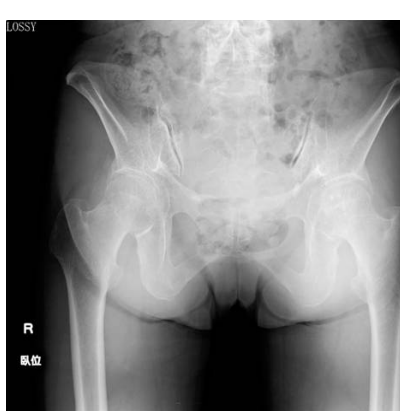

(a)

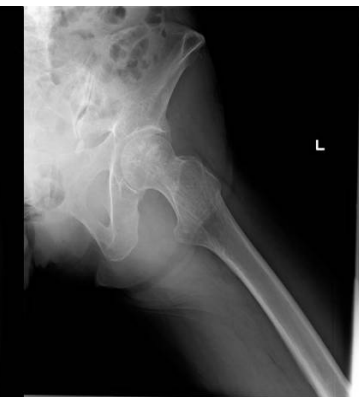

(b)
Figure 3. (a) Standard radiographs of an occult fracture at the left superior pubic ramus in case 2; (b) Lateral view. We could not detect a fracture line in both antero-posterior and lateral views.

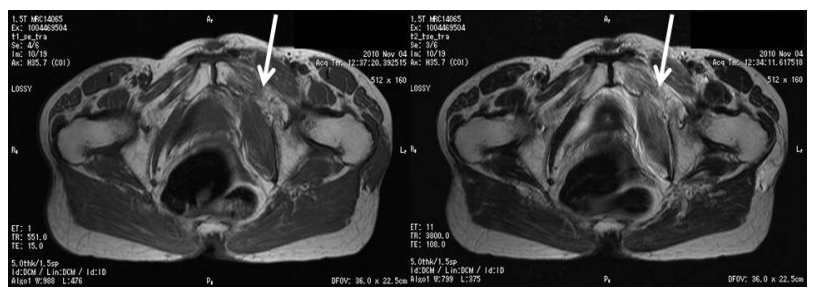

(a)

(b)

Figure 4. (a) On axial T1-weighted images, a fracture line extends towards the superior pubic ramus; (b) On axial T2-weighted images, a diffuse high intensity area exists in the external obturator muscle.

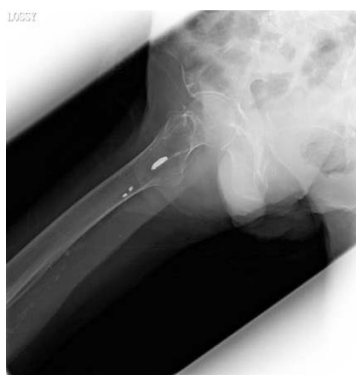

(a)

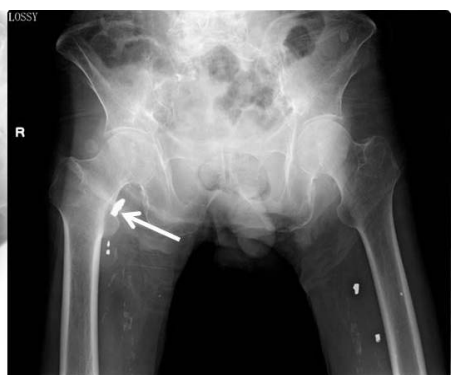

(b)
Figure 5. (a) Standard radiographs of an occult fracture at right superior pubic ramus in case 3; (b) Lateral view. We could not detect fracture a line in either view. We could detect bullet implantation (white arrow). utilized. We could detect a fracture line at the inferior pubic ramus (Figure 6). One month later he could walk after a period of conservative treatment.

\subsubsection{Case 4}

A 43-year-old female with anorexia nervosa did not have a traumatic episode but complained of left groin pain. At the initial visit she could walk with assistance and we did not detect a fracture line in this radiograph (Figures 7(a) and (b)). Three weeks later radiographs were obtained that revealed a fracture line in her left pubic ramus (Figure 8). One month later she could walk after a period of conservative treatment.

\section{DISCUSSION}

Thirty cases of occult fractures of the ischiopubic rami have been examined during a time frame of 2 years and 9 months. Nine cases were of insufficiency fractures without a traumatic episode. Most likely due to osteoporosis, the fracture site was in the superior pubic rami in 6 patients as the superior pubic rami is a stress site during weight bearing.

Ischiopubic fractures can also occur after operations around the hip joint. Christiansen CG reported stress pubic fractures after total hip arthroplasty [7]. Tsuboi M reported stress pubic fractures after rotational acetabular osteotomies [8].

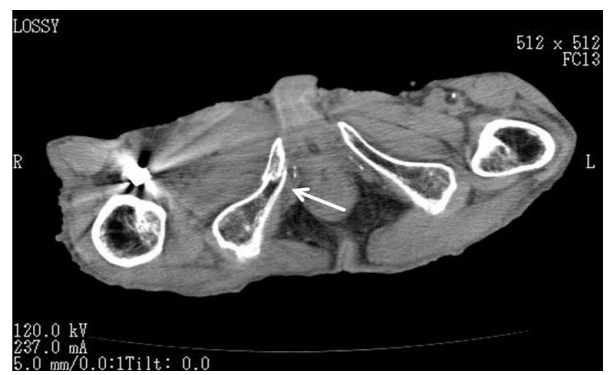

Figure 6. On axial CT image, we could detect a fracture line at the inferior pubic ramus.

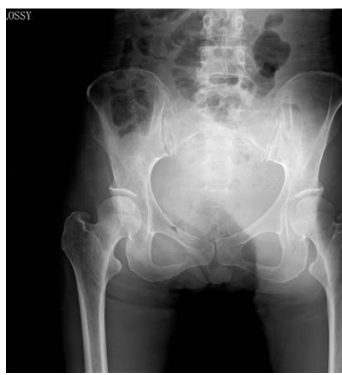

(a)

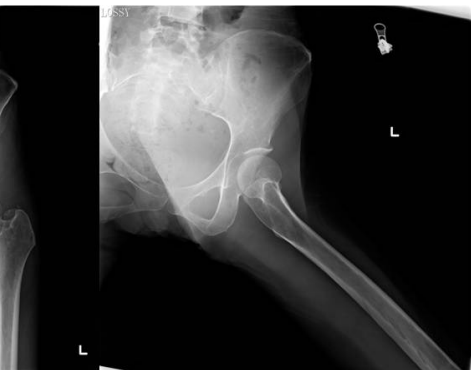

(b)
Figure 7. (a) Standard radiographs of an occult fracture at left superior pubic ramus in case 4; (b) Lateral view. We could not detect a fracture line in both the antero-posterior and lateral views. 


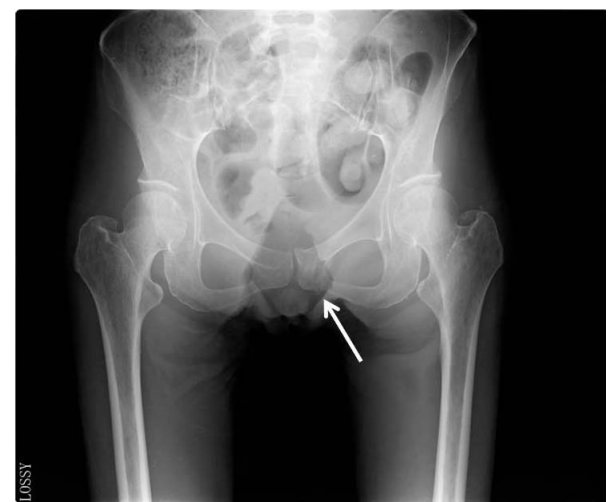

Figure 8. Repeated radiographs 3 weeks after the initial visit revealed a fracture line at the pubic ramus.

The ambulatory status at the initial visit varied from bed ridden to standing up with an aid and walking with an aid. Physical findings can include tenderness at the fracture site, negative straight leg raise, and pain upon weight bearing. Cabarrus, M.C. reported MRI is more useful to detect the occult fractures than $\mathrm{CT}$ around the pelvis [6]. In some cases patients could walk with assistance, so if obtaining an MRI was expensive or MRI was not accessible, repeated radiographs were utilized.

In 2 cases, we could not use MRI because of bullet implantation or the presence of a pacemaker. Although MRI is superior in detecting occult fractures, CT scan can be utilized in cases where MRI cannot be used.

Lee SW reported the usefulness of bone scintigraphy to detect stress pubic fractures [9]. Bone scintigraphy or $\mathrm{CT}$ is usehul to detect stress fractures; however, to avoid radiation, MRI is preferred over radiography.

Regarding treatments, Beall DP reported on percutaneous bone cementing [10]. In our cases presented above, we treated conservatively without restriction of weight bearing or activities. After 2 months we reexamined patients and found complete fracture healing without pain.

\section{CONCLUSION}

In forming the differential diagnosis for hip pain, we must be careful to consider fracture even in the absence of radiologic evidence. Follow up imaging including MRI or CT scan continues to be recommended in cases where the differentiation of femur from pubic rami fractures is important. It is also important to remember that insufficiency fractures can occur without a traumatic episode and that the ambulatory status at the initial visit varied from bed ridden to standing up with an aid and walking with an aid. In patients with a pacemaker, bullet implantation, or an artificial joint, CT or repeated radiographs are useful in detecting occult fractures.

\section{REFERENCES}

[1] Iwata, T., Nozawa, S., Dohjima, T., Yamamoto, T., Ishimaru, D., Tsugita, M., Maeda, M. and Shimizu, K. (2012) The value of T1-weighted coronal MRI scans in diagnosing occult fracture of the hip. Journal of Bone and Joint Surgery (British Volume), 94, 969-973. doi:10.1302/0301-620X.94B7.28693

[2] Sankey, R.A., Turner, J., Lee, J., Healy, J. and Gibbons, C.E.R. (2009) The use of MRI to detect occult fractures of the proximal femur. Journal of Bone and Joint Surgery (British Volume), 91, 1064-1068. doi:10.1302/0301-620X.91B8.21959

[3] Peter, F.R., et al. (1993) Diagnosis of occult fractures about the hip. Magnetic resonance imaging compared with bone-scanning. Journal of Bone and Joint Surgery (American Volume), 75, 395-401.

[4] Burger, P.E., Ofsten, R.A., Jackson, D.W., Morrison, D.S., Silvino, N. and Amador, R. (1989) MRI demonstrations of radiographically occult fractures. What have we been missing? Radiographics, 9, 407.

[5] Ganiyusufoglu, A.K., Onat, L., Karatoprak, O., Enercan, M. and Hamzaoglu, A. (2010) Diagnostic accuracy of magnetic resonance imaging versus computed tomography in stress fractures of the lumbar spine. Clinical Radiology, 65, 902-907. doi:10.1016/j.crad.2010.06.011

[6] Cabarrus, M.C., Ambekar, A., Lu, Y. and Link, T.M. (2008) MRI and CT of insufficiency fractures of the pelvis and the proximal femur. American Journal of Roentgenology, 191, 995-1001. doi:10.2214/AJR.07.3714

[7] Christiansen, C.G., Kassin, R.A., Callaghan, J.J., et al. (2003) Pubic ramus insufficiency fractures following total hip arthroplasty: A report of six cases. Journal of Bone and Joint Surgery (American Volume), 85, 1819-1822.

[8] Tsuboi, M., Hasegawa, Y., Fujita, K. and Kawabe, K. (2011) Pubic/ischial stress fractures after eccentric rotational acetabular osteotomy. Journal of Orthopaedic Science, 16, 38-43. doi:10.1007/s00776-010-0010-6

[9] Lee, S.W. and Lee, C.H. (2005) Fatigue stress fractures of the pubic ramus in the army: Imaging features with radiographic, scintigraphic and MR imaging findings. $\mathrm{Ko}-$ rean Journal of Radiology, 6, 47-51. doi:10.3348/kjr.2005.6.1.47

[10] Beall, D.P., Datir, A., D’Souza, S.L., D'Souza, L.S., Gunda, D., Morelli, J., Johnson, M.B. and Nabavizadeh, N. (2010) Percutaneous treatment of insufficiency fractures: Principles and review of literature. Skeletal Radiology, 39, 117-130. doi:10.1007/s00256-009-0722-x 